\title{
القبائل العطاوية بجبال صاغرو، من الترحال والانتجاع إلى الاستقرار خلال مطلع القرن 21: مظاهر التجديد في \\ استغلال المجال الجبلي
}

Al- Atawiya tribes in the Saghro Mountains from nomadism and transhumance to stability during the beginning of the 21st century: manifestations of renewal in the exploitation of the mountainous areas

مصطفى جدية بن امبارك(1) محمودي زكرياء بن عبدالله(2) محمودي سليمان بن عبدالله(3)

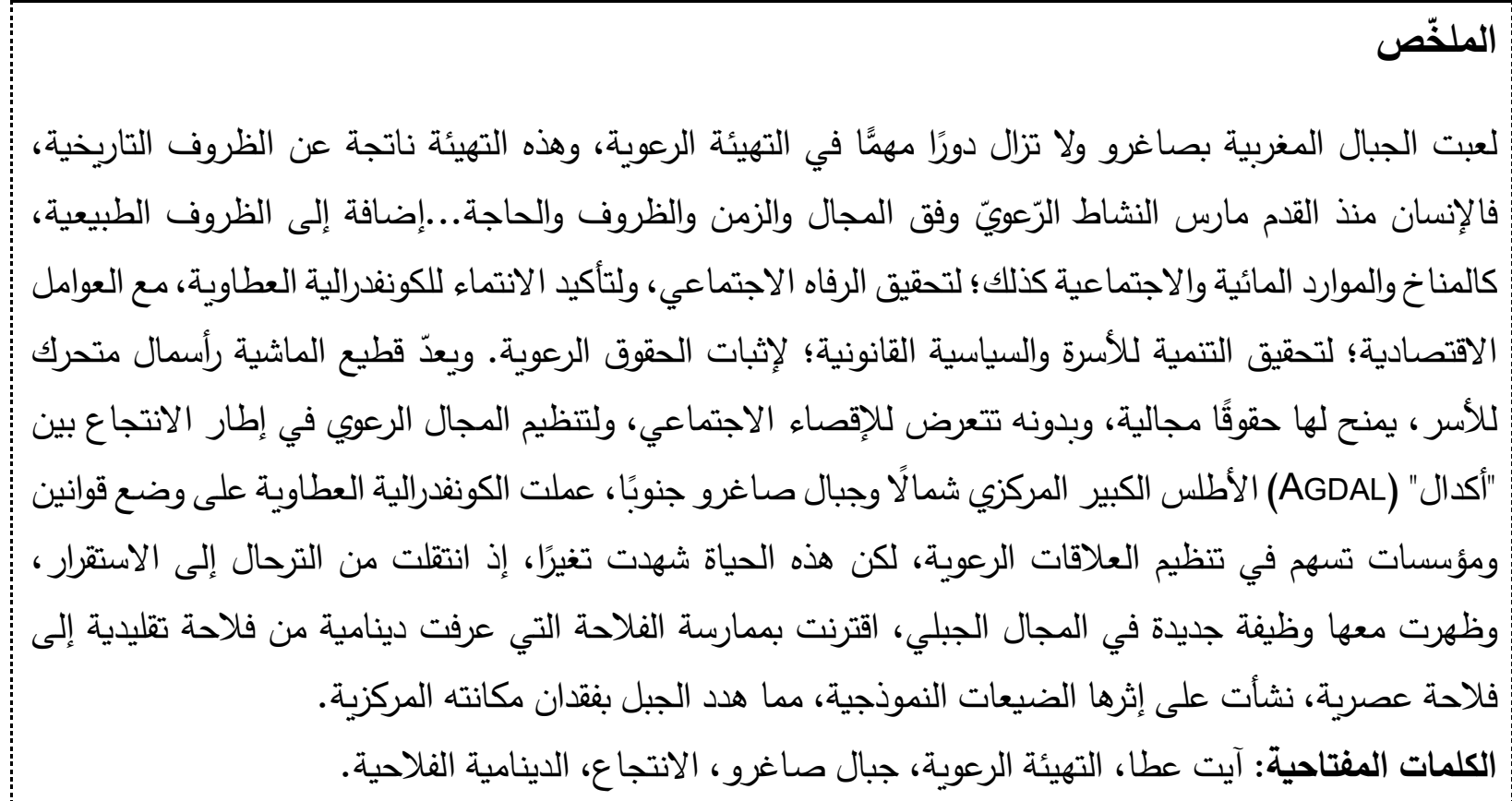

\section{Abstract}

The Moroccan mountains have been playing an important role in the pastoral planning. The latter is a product of historical conditions. Since ancient times, man has practiced pastoral activity according to the area, time, circumstances and need... in addition to the natural conditions such as the climate and water resources as well as the social ones in order to achieve social welfare and confirm belonging to the Al- Atawiya Confederation, the Economic factors in a bid to achieve the development of the family, and finally the political and legal ones to prove pastoral rights. The herd is considered a moving capital for families, granting them territorial rights.

Without it, it would be subjected to social exclusion. in order to organize the pastoral field within the framework of the transhumance between Agdal, the central high Atlas in the north and the mountains of Saghro to the south, the Al- Atawiya Confederation worked to legislate laws and set up institutions that would contribute to regulating pastoral relations. But this life witnessed a change; it moved from nomadism to stability, with a new job coming to the fore in the mountainous field, which was associated with the practice of agriculture that witnessed a dynamic from traditional to modern agriculture, giving rise to the emergence of the model farms, which threatened the mountain to lose its central position.

Keys Words: Ayt Atta, Pastoral Planning, Mountain of Saghro, Transhumance, Agricultural Dynamics

(1) قسم الجغرافيا، كلية الآداب والعلوم الإنسانية، جامعة المولى اسماعيل مكناس (2) قسم الجغرافيا، كلية الآداب والعطوم الإنسانية، جامعة المولى اسماعيل

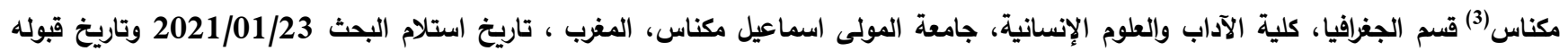


يحظى المغرب بوحدات جبلية متنوعة، إذ توجد جبال الريف بمناطقه الثمالية وجبال الأطلس بمستوياتها الثلاثة: الكبير والمتوسط والصغير ، المنتشرة في أنحاء شتّى من البلاد، تمارس هذه الوحدات وظائف إيكولوجية بيئية وأخرى اقتصادية،

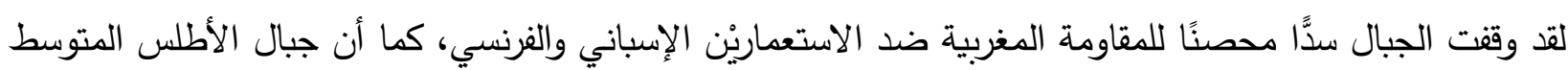
تعدّ خزانًا مائيًّا بامتياز • في ورقتنا البحثية هذه نروم مقاربة الجبل من جهة الدور الاقتصادي الذي جعله يشكّل مجالًا

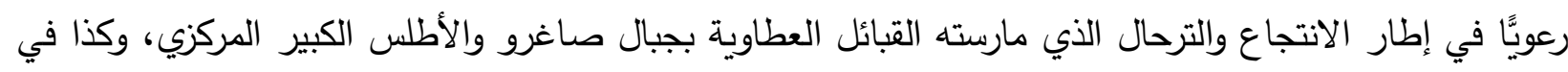
إطار الاستقرار الذي أسهم في تغيير شكل استغلاد المجالات الغابوية بدينامية فلاحية تغيرت معالمها من الإطار التقليدي إلى الإطار العصري، فما هي مميزات مرحلة الانتجاع والترحال؟ ما هي خصائص مرحلة الاستقرار؟ ما هي

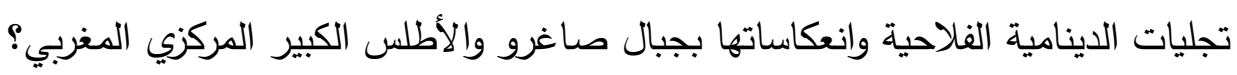
1-مرحلة الترحال والانتجاع عند القبائل العطاوية بجبال صاغرو والأطلس الكبير المركزيّ 1-1 تقلبات المراعي من أسس التشبث بالترحال عند القبائل العطاوية بجبال صاغرو

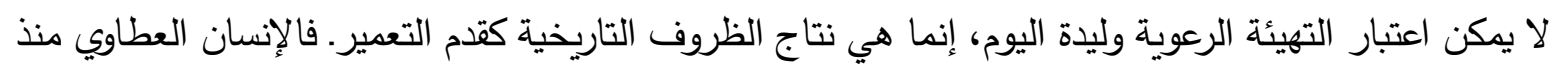
القدم مارس النشاط الرعوي وفق المجال والزمن والظروف والحاجة... إضافة إلى الظروف الطبيعية أو الطبوغرافية،

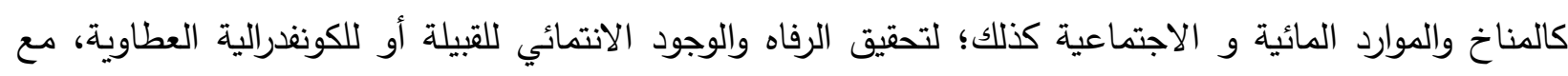
العوامل الاقتصادية؛ لتحقيق التنمية للأسرة والسياسية القانونية؛ لإثبات الحقوق الرانية الرعوية.

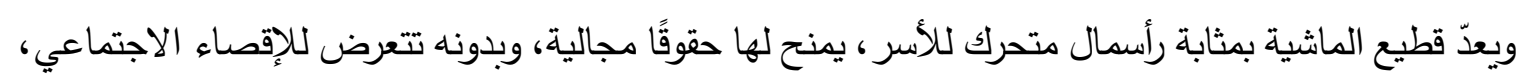

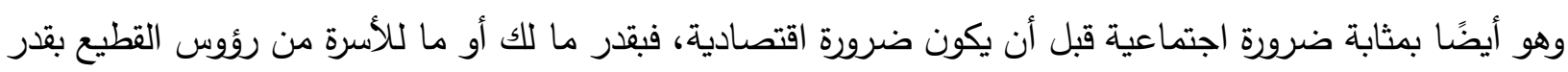

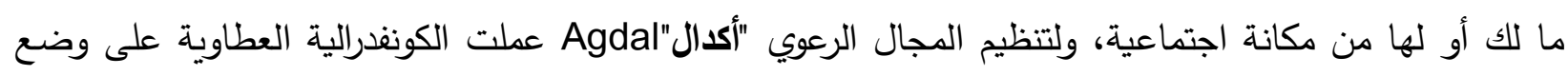
قوانين ومؤسسات تسهر على تتظيم العلاقات الرعوية بين سكان مجال "أسامر"Asamer شتاء من السفوح الجنوبية

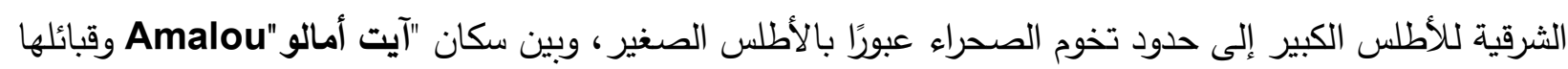
صيفًا في السفوح الثمالية للأطلس الكبير المركزي والأطلس المتوسط. فالانتجاع والتعزيب بين جبال صاغرو والأطلس الكبير المركزي الذي تمارسه الكونفدرالية العطاوية يتحرك ما لاطئ بين 120الى150 خيمة تبعًا لغنى المراعي، وأهمية منابع الماء، سواء أكانت في الملكية الفردية أم الملكية المشتركة، حيث يتحرك الرُّحّل الرُّعاة بصحبة مواشيهح وفق تقلبات المراعي، ويتناوبون كل سنة في بعض الأسر على حراسة المواشي ليلً داخل مساحة ضيقة مسيّجة بالحجارة أو بالأشواك وبعض الأشجار والنباتات التي تسمى محليًّ "أمزاغ".

ولإخضاع المنتجعين للانضباط واحترام النظام العام يتم تعين مؤسسة جماعة القبيلة شيخ المراعي، الذي يتم اختياره بناء على مدى معرفته في مجال تنقّل الرحل ومدى قوته وشهامته، علاوة على كرمه وحسن سمعته، لكن القبائل

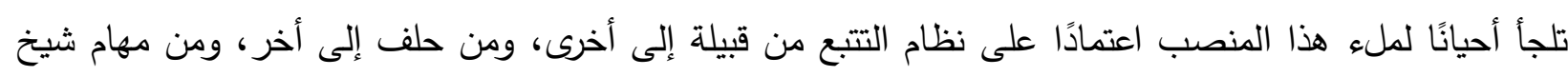

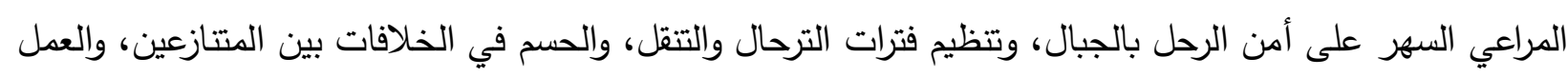

على تحديد مجال كل قبيلة. (2)

(1) - Auclair Laurent et Alifriqui Mohamed, Agdal patrimoine socio-écologique de l'Atlas Marocain, RD, 2012 P198 (2) استيتيتو عبد الله، التاريخ الاجتماعي والسياسي لقبائل آيت عطا الصحراء إلى نهاية القرن التاسع عشر، منشورات المعه الملكي للثقافة الأمازيغية، 


\section{1-2-1 أهية التدجين الرعوي عند قبائل آيت عطا بجبال صاغرو}

عرفت الأودية الجبلية بجبال صاغرو منذ القديم تعميرًا بشريًا واستغلالًا كثيفًا، رسمت ظروفي عروف البيئة الثحيحة معالمه الكبرى رغم تنوع مكوناتها وتكاملها، مما أدّى إلى تفرّد النطاق الجبلي بأنشطة التدجين ونطاق الواحات وبطون الأودية بالزراعة.

\section{1-2-1 الدور الاقتصادي والاجتماعي عامل أساسيّ لتربية الماشية بجبال صاغرو}

فرضت البيئة الجبلية بصاغرو الاتجاه نحو اقتصاد مبني على التكامل بين الزراعة الواحية والتربية الواسعة

للماشية بالمرتقعات، ويحظى القطيع بأهمية بالغة؛ لاندماجه مع شتّى عناصر البيئة الهشة، مما تُلجئ الفلاح إلى بيع لئي بعض رؤوس قطيعه عند الحاجة لشراء الأدوات الفلاحية والبذور ، ولإقامة الحفلات واستصلاح المنزل أو بنائه، وشراء باء باء الأرض أو استصلاحها، وأداء الضرائب... وتكون عنده بمثابة خزينة مربحة، بينما تتحكّم في الزراعة ضوابط طبيعية محددة كقلة الماء والتربة، لذا يفضّل الفلاح بصاغرو الاستثمار في قطاع الماشية، وإن قلت إمكانياته.

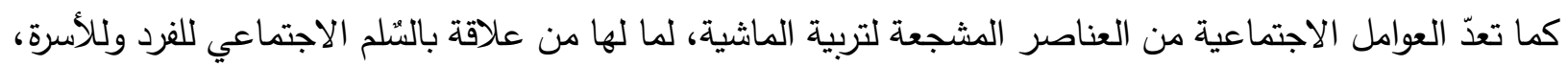

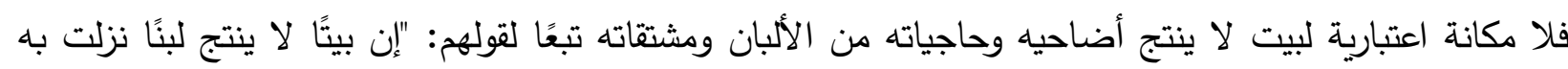
اللعنة"، وتعدّ الماشية الوسيلة المثلى لاستغلال الحقوق المترتبة للانتماء القبلي على أراضي الجموع، إذ بدونها ينتقل هذا الحق إلى الآخرين من غير منازع، إضافة إلى أهمية روث الناشية في تخصيب الأراضي الزراعية.

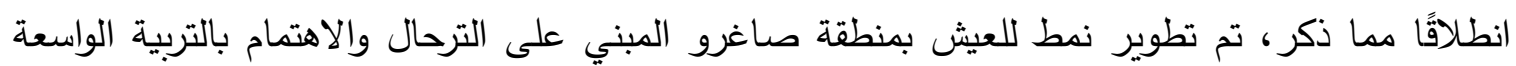

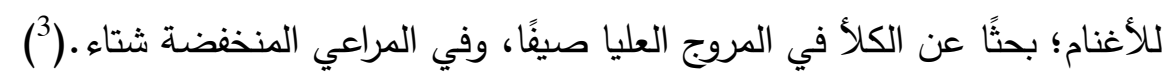

وفي المنطقة الجنوبية عند السفوح الصحراوية بجبال الأطلس الكبير والصغير تتمركز قبائل آيت عطا ببطونها،

كآيت سفول، وآيت واحليم، وآيت علوان... وتمارس ترحالًا دوريًا، وهذه القبائل تعيش على ماشية، تشكّل نسبًا مهمة

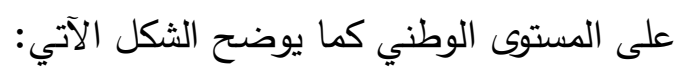




\section{مبيان رقم1: توزيع نسبة مساهمة قطيع الماشية بجبال صاغرو على المستوى الوطني سنة2014}

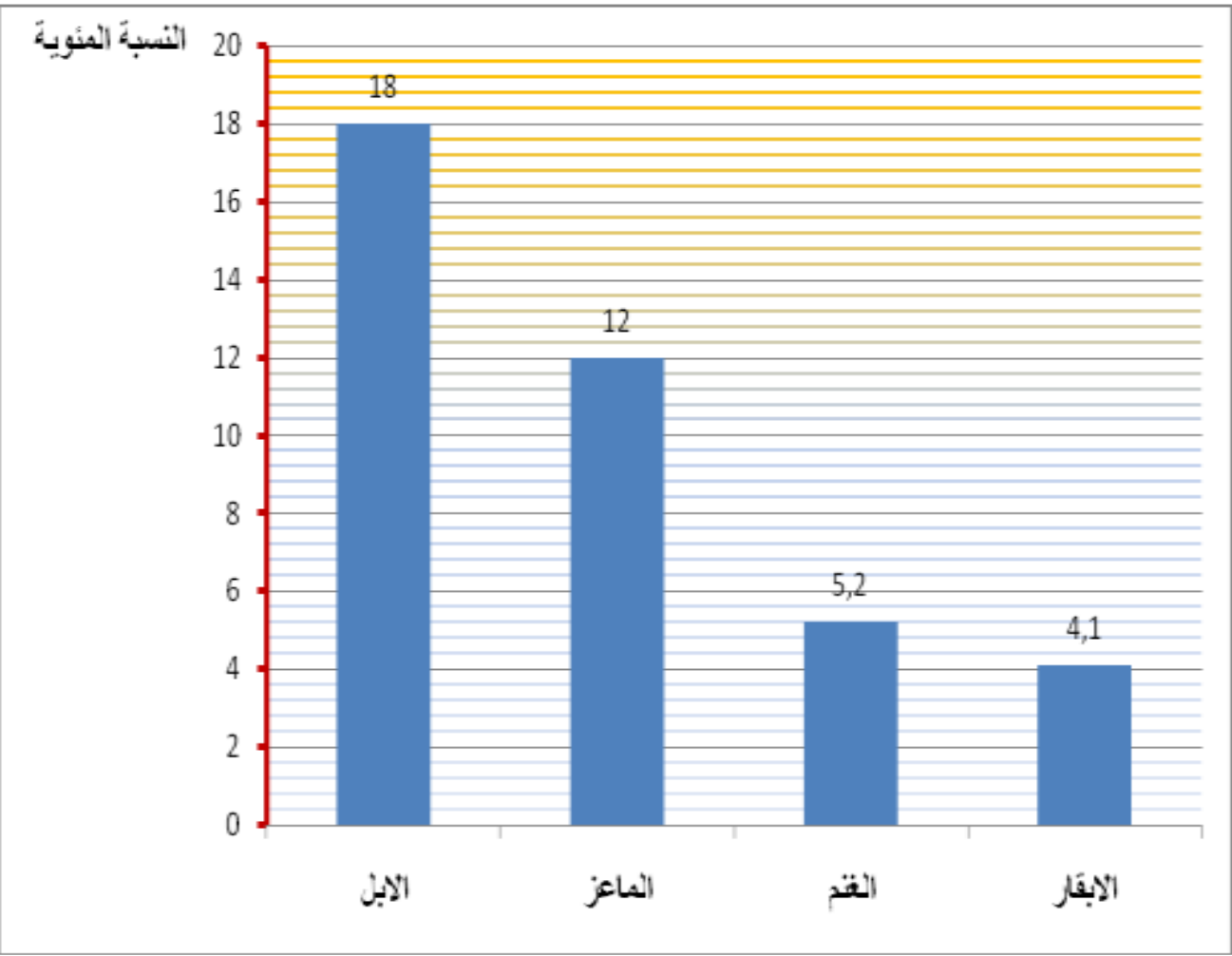

المصدر : المكتب الجهوي للاستثمار الفلاحي بتافيلالت2020

2-2-1

تعدّ مسألة الإلمام بمكونات قطاع تربية الماشية -عند الرعاة والرحل المتنقلين في إطار الانتجاع، ودورها في

الاقتصاد المحلي للمناطق الجبلية والنطاقات شبه الصحراوية عامة، وجبال صاغرو خاصة- مسألة عويصة، فالإحصاءات بهذا القطاع قد لا نجدها إلا في كنانيش الضريبة الفلاحية سنة 1953، والإحصاء الفلاحي سنة 1996، كما يوضّحه الجدول الآتي:

جدول رقم 1 تطور أصناف المواشي بجبال صاغرو

\begin{tabular}{|c|c|c|c|c|}
\hline الإبل & الأبق & المعز & الغنم & الصنة/ الصن \\
\hline 2730 & 197 & 2353 & 2572 & 197 \\
\hline 0 & 5 & 2 & 6 & 7 \\
\hline 2794 & 199 & 2756 & 3112 & 197 \\
\hline 5 & 7 & 5 & 5 & 8 \\
\hline 2812 & 202 & 2836 & 3254 & 197 \\
\hline 1 & 3 & 4 & 7 & 9 \\
\hline 2742 & 200 & 3055 & 3396 & 198 \\
\hline 0 & 8 & 8 & 3 & 0 \\
\hline
\end{tabular}




\begin{tabular}{|c|c|c|c|c|}
\hline 2567 & 216 & 3105 & 3489 & 198 \\
3 & 5 & 1 & 7 & 1 \\
\hline 2522 & 340 & 2916 & 3902 & 199 \\
1 & 1 & 4 & 2 & 6 \\
\hline
\end{tabular}

المصدر : كنانيش الضريبة الفلاحية بورزازات والإحصاء الفلاحي1996

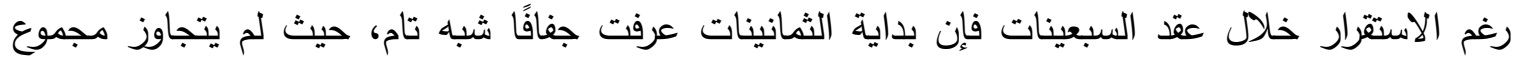

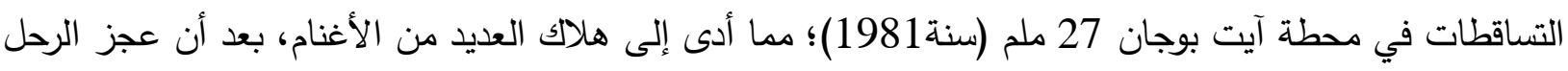

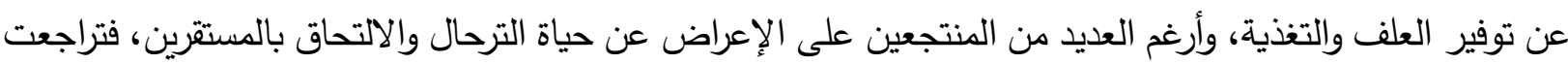

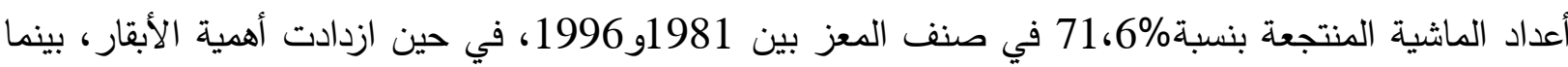
حافظت الإبل على مستوى متقارب من أعدادها.

2-1 3-2-1 تربية الماشية، آلية من آليات التكيف مع الندرة بجبال صاغرو.

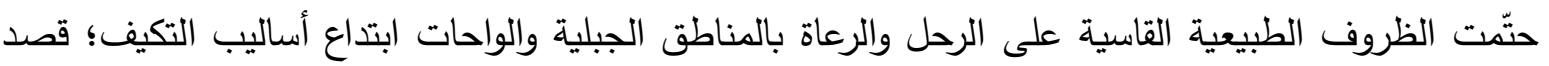

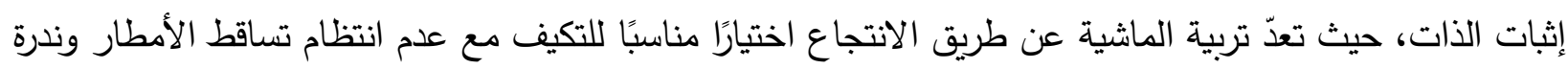

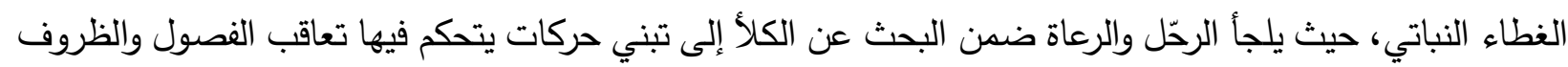

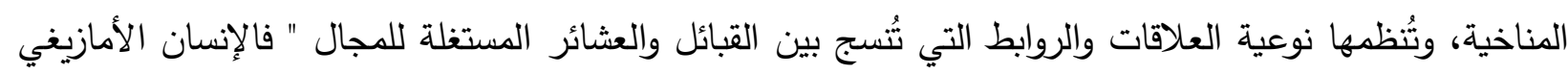

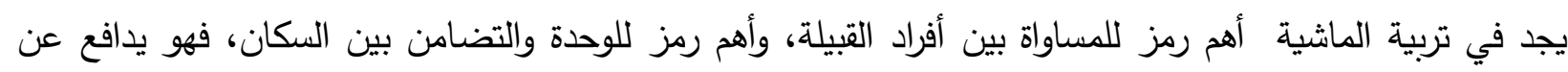

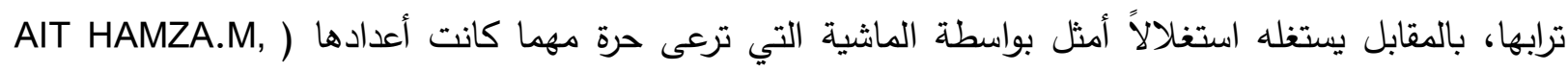

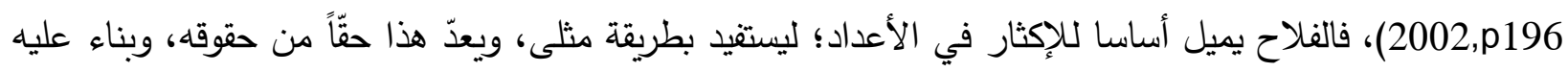

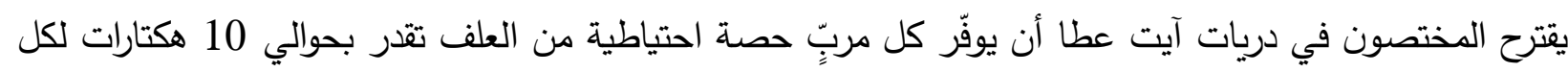

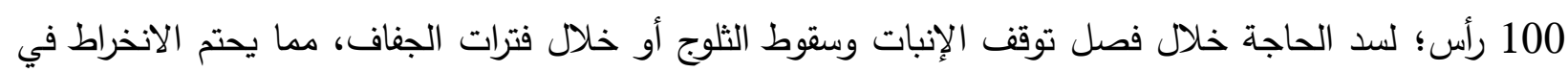
الحركة الأفقية للقطعان بين المسارح. إن الحركات المجالية للماشية وعمليات البيع والثراء آليتان من الآليات الاستراتيجية التي يلجأ إليها الرحّل

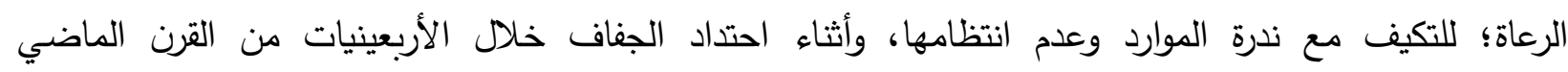

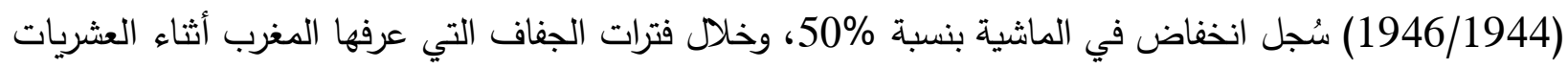

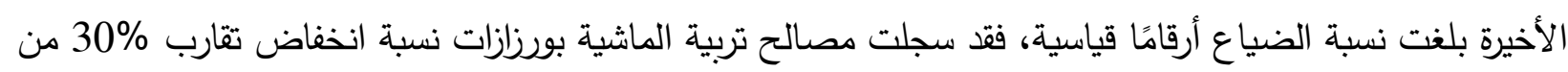

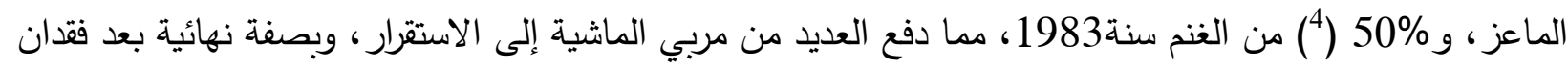

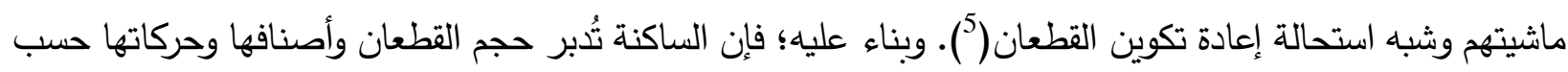

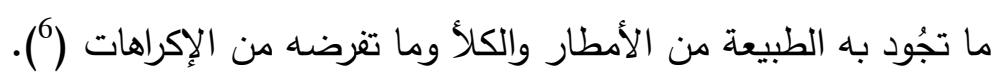

$$
\text { (5) (آيت حمزة محمد، مرجع سابق ص الجناء } 85
$$

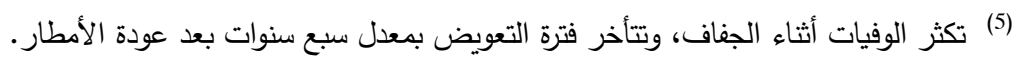

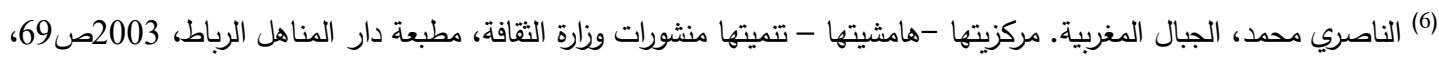




\section{-1 - 3-1 المرتفعات الجبلية، مجال خصب للرعي}

تحدد المؤهلات الجغرافية أنماط استغلال الدجال، حيث تتحكّم مواقيت تساقط الأمطار والثلوج وفترات الإنبات

في توزيع مناطق تربية الماشية، سواء من حيث أعدادها أو أصنافها.

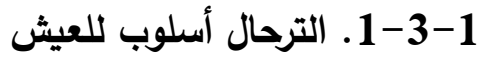

يعدّ الترحال أولًا ظاهرة اقتصادية واجتماعية، لا تبرز إلا إذا توفرت مجموعة من العوامل التي تحددها الظروف التهات

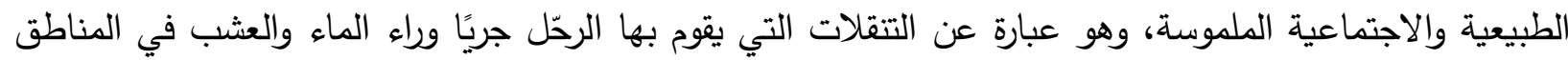

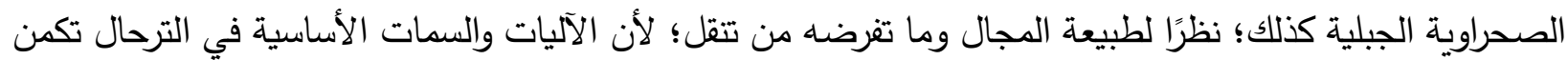
في التمركز حول آبار المياه في المواسم الجافة، أو تتقلات نحو المناطق ذات التراتهات المراعي الوافرة.

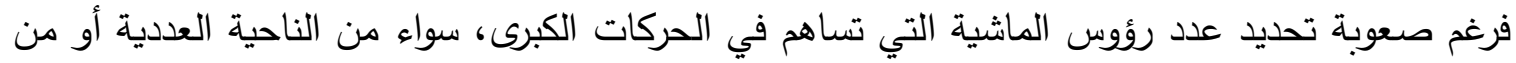

الناحية النوعية وتأثيراتها الإيكولوجية والبشرية، فمن المؤكد أن للتدجين أهمية بالغة في حياة الساكنة.

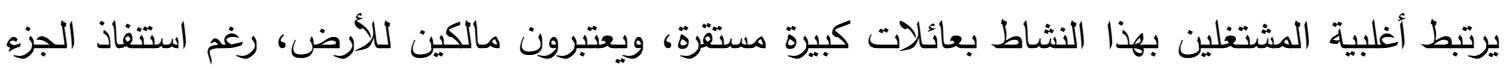
الأكبر من حياتهم في التتقل وراء القطعان، وفق نظام تغرضه الظروف البيومناخية والمحددات البشرية. وتتكون الأسر

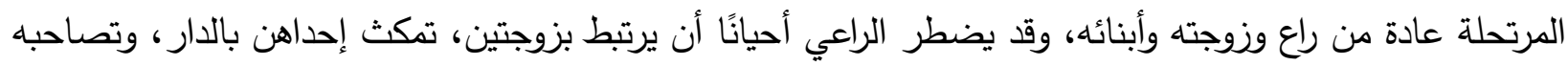

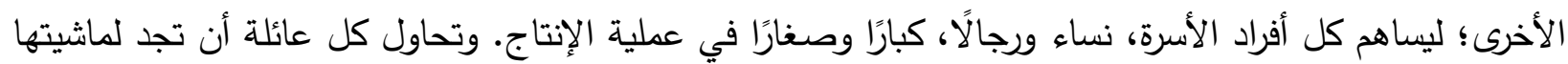

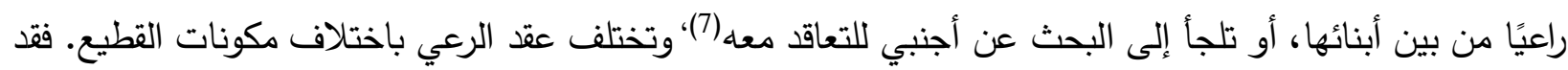

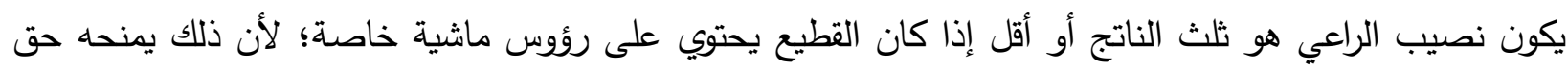

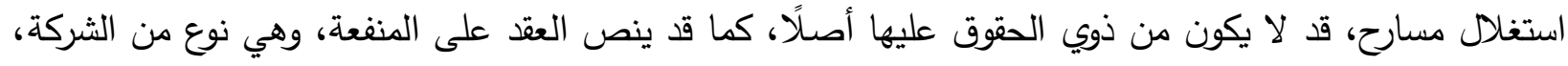

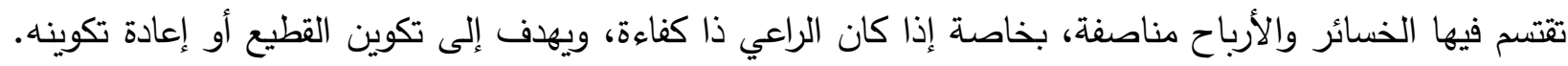

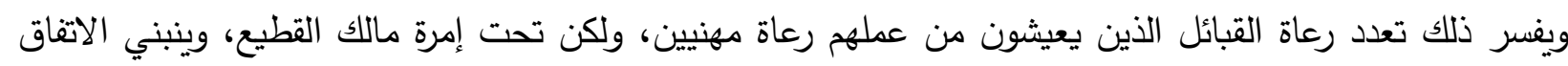

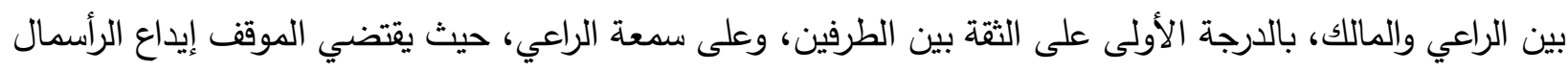

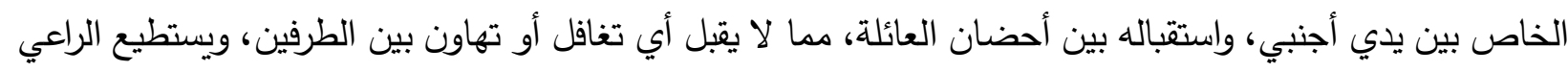

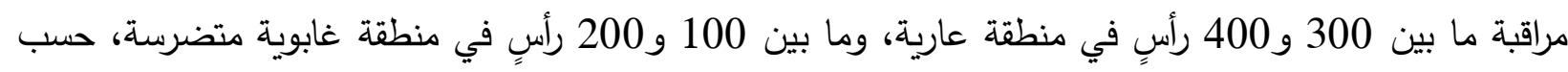

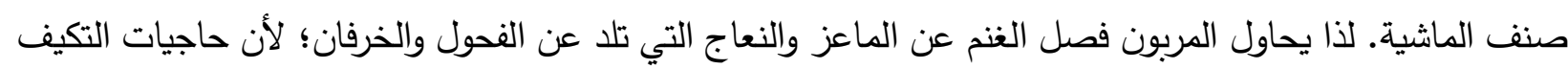
وإمكاناته متباينة.

تُجهز قافلة للترحال قد تزيد عن 10 دواب، تحمل المؤن والخيام والأثاث الذي قد لا تتجاوز مكوناته: مِغلاة ماء وطاحونة حجرية وصندوق يحوي المواد الغذائية وقِرَب ومنوال... يركض الأطفال والنساء مشياً على الأقدام وراء

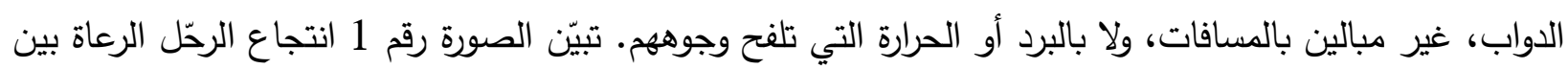
جبال صاغرو بالأطلس الصغير وجبال الأطلس الكبير المركزي. 


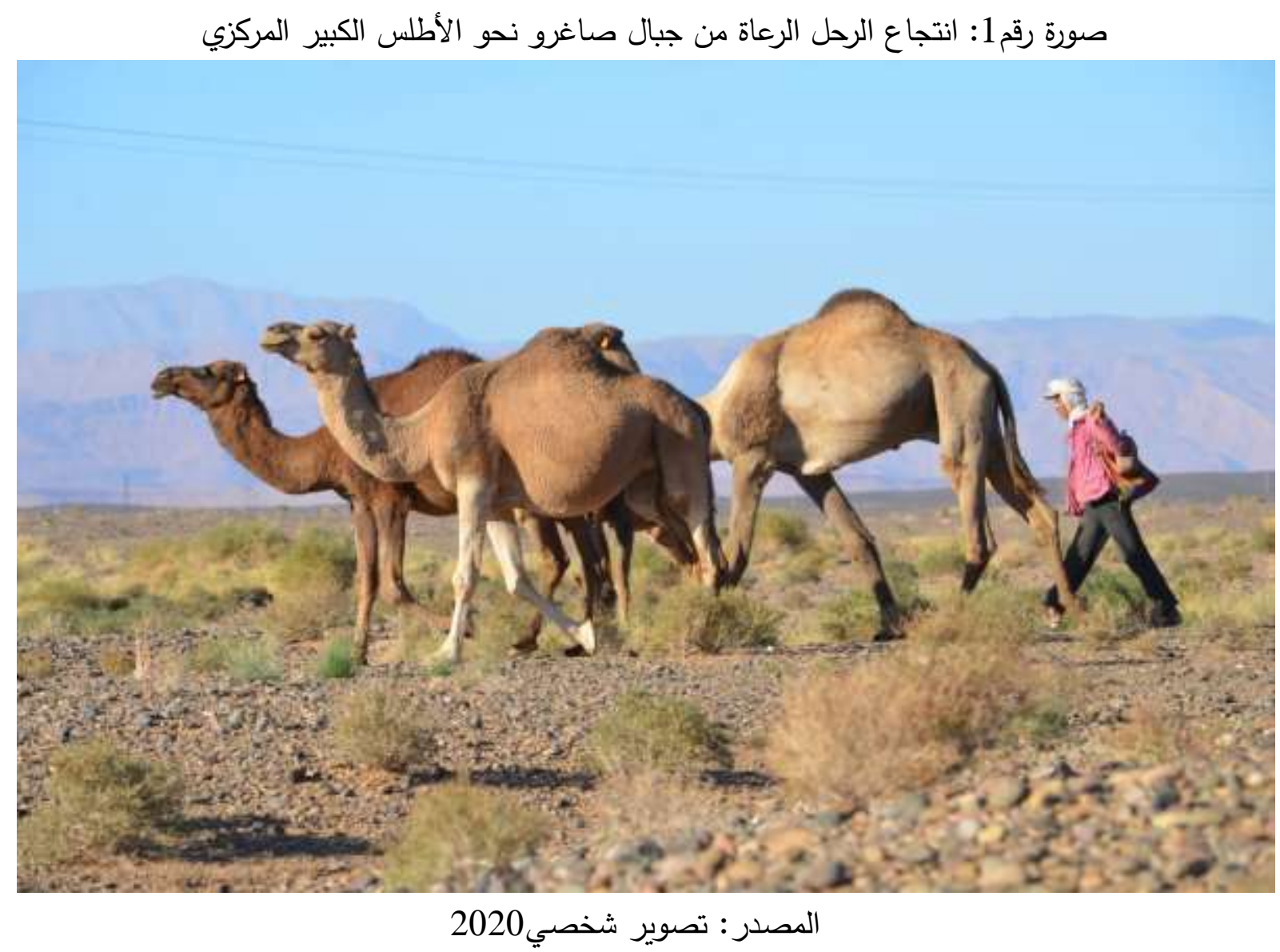

هذا المشهد في الصورة أعلاه اعتاد سكان الأودية الجبلية رؤيته مع حلول كل فصل ربيع اتجاه القهم، وفي بداية كل خريف اتجاه الأسافل. إنها رحلة الثتاء والصيف التي حددت فصول السنة والظروف الطبيعية إيقاعها قبل أن تأتي مستحدثات العقود الأخيرة على كثير من معالمها.

1-3-2 أعراف الرعي وحقوقه عند القبائل العطاوية أثناء انتجاعها بجبال الأطلس الكبير المركزي وجبال صاغرو يضطر مالكو قطعان الماشية؛ لمسوّغات بيومناخية أن تتنقل عبر تراب المجموعة وخارجه، باحثة عن الكلأ والماء؛ مما قد يؤدي إلى احتكاكات واصطدامات، تتواتر لتَستج خيوطها تاريخ المنطقة، حيث تتحكم الظروف التاريخية والمصالح الاقتصادية والعلاقات البشرية في توسيع مجال الرعي أو انكماشه. والخريطة الآتية تحدد مجالات تتقل الرحل الرعاة بين جبال صاغرو وجبال كنات بالأطلس الصغير في اتجاه الأطلس الكبير المركزي. 


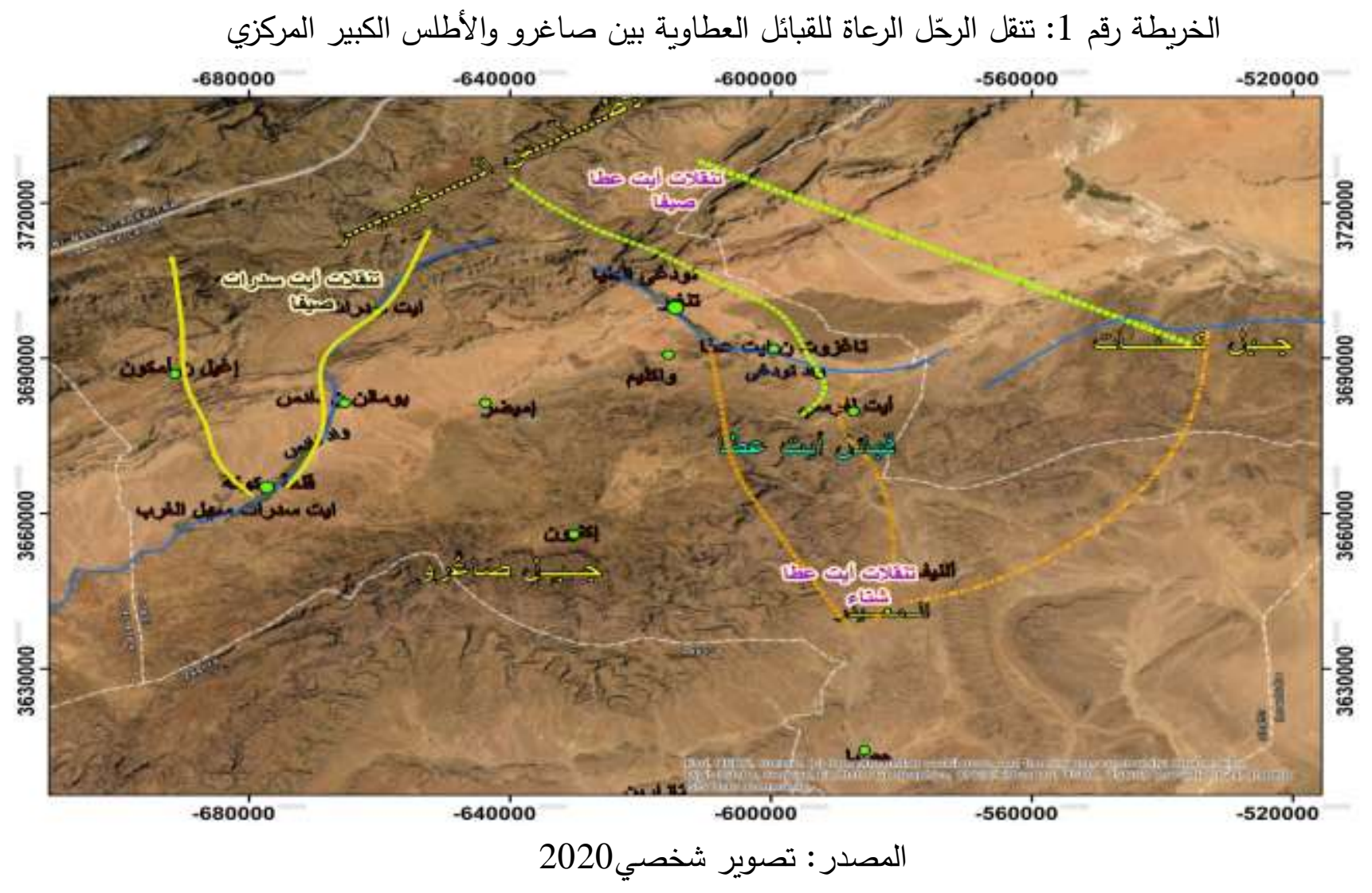

إن الرحل الرعاة بصاغرو يستغلون المجال المخصص للقبيلة، والمنصوص على حدوده كالتالي:" تزي-ن آيت إمي - قمم وَاؤكلزات- تزي -ن - كَران شمالًا، خط تقسيم المياه بين حوض دادس وحوض أسيف امكون من الثرق

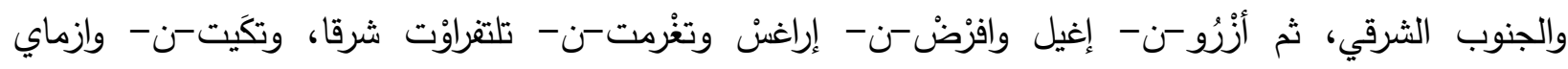
جنوبا..."("8)، وأراضي قبائل إمغران وآيت بوكماز وآيت إصحا وآيت عطا وآيت سدرات. وضعية كثيرًا ما تسبب الشجار

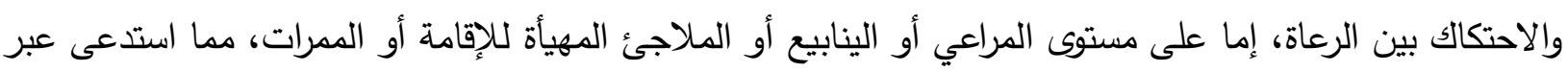

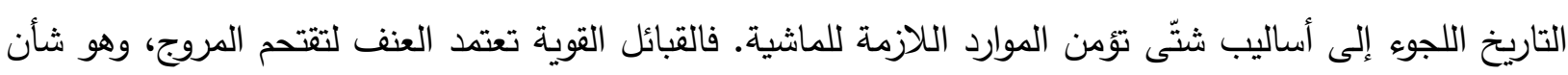
الاتحادية العطاوية التي استطاعت خلال القرن 16، وبمساعدة زاوية أحنصال أن تغرض سيطرتها على المراعي الصيفية في الأطلس الكبير حتى سهل تادلة، وأن تُخضِع لنفوذها تراب قبائل امكونة وآيت سدرات وآيت دادس وإمغران

.(Paul Pascon, 1983,p253) وبعد تلاشي وطأتها؛ أصبح الوئام والتضامن قصد التكامل طريقة للحصول على المراعي، حيث أُبرِمتْ عُقود التآخي

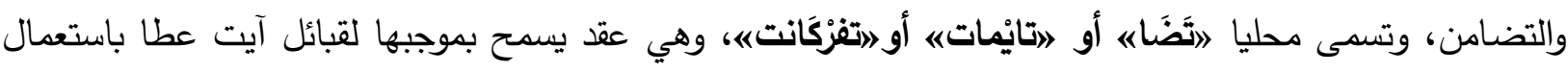

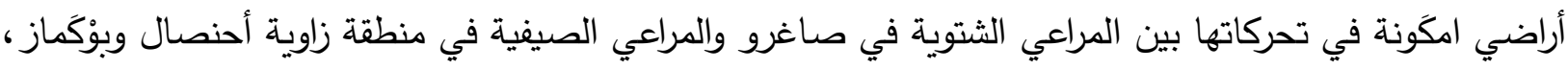

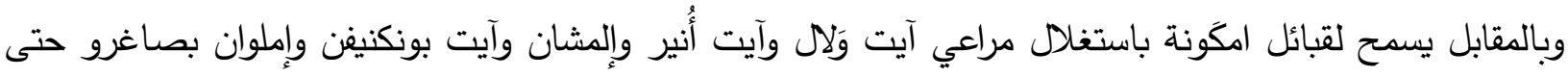

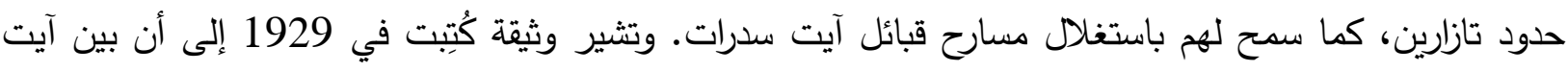
سدرات (9) وامكونة عقد تَفركانت، وأن الأولى سمحت لقبيلة امكونة باستعمال مسارحها بصاغرو "بالخير" شريطة الالتزام بما يلي: 
-لا يحق لسكان امكونة أن يجمعا الدمل بعد مغادرتهم لمكان الإقامة، أي ليس لهم الحق في جمع حطب التدئة وكلاً

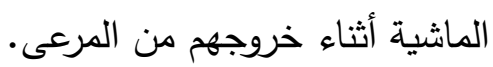
-لا يحق لسكان امكونة أن يقوموا بالاحتطاب، بينما يسمح لهم باستعمال الأخشاب الميتة لغير الفحم والبيع.

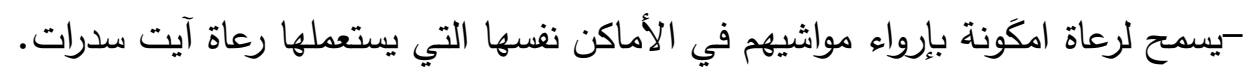

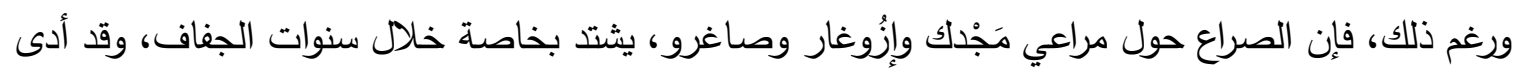

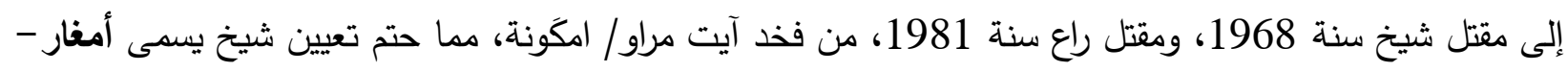

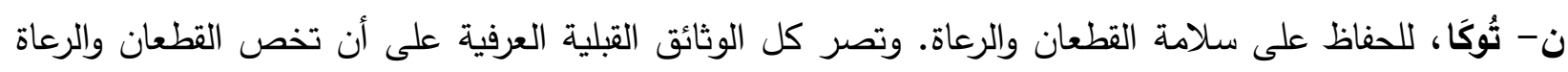

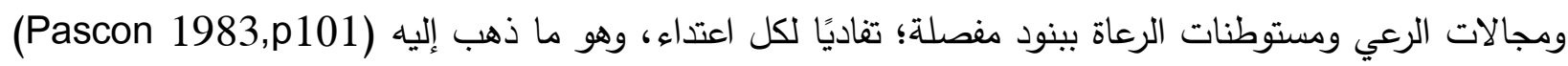

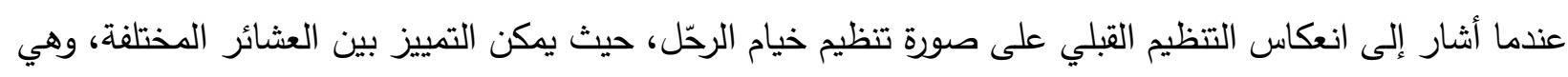

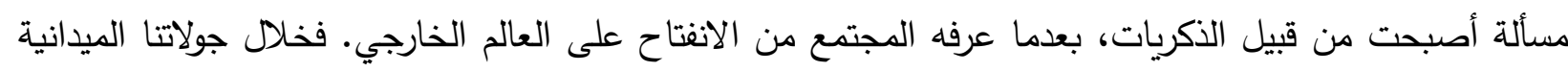

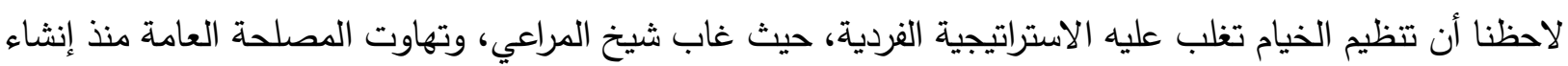

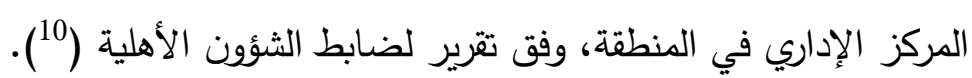

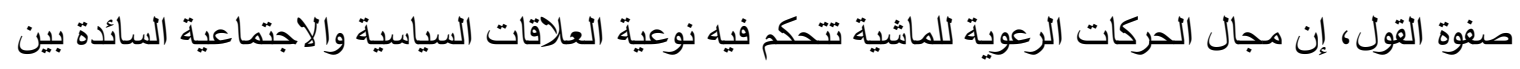

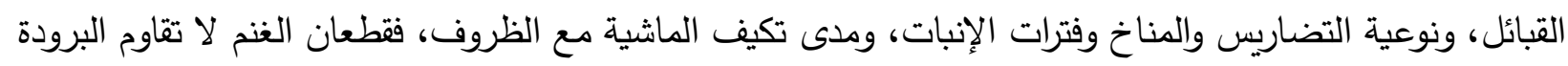
ولا الحرارة، بينما يصد الماعز لقدرته على استغلال الظروف التضاريسية والنباتية الوعرة.

\section{1-3-3 رحلة الصيف الصاعدة نحو جبال الأطلس الكبير المركزي}

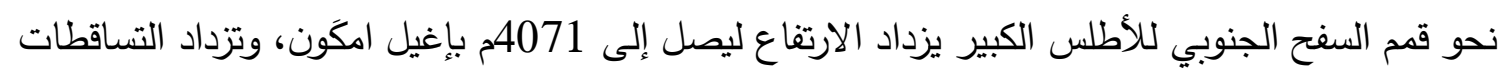

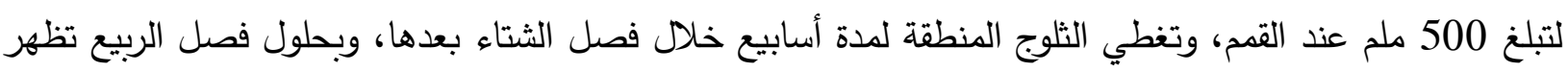

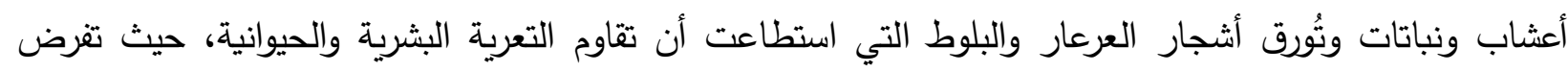

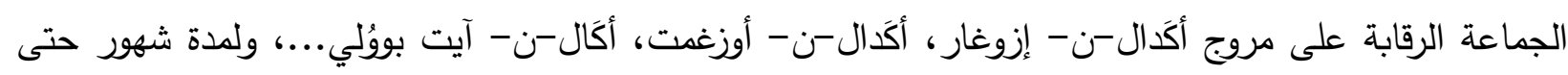

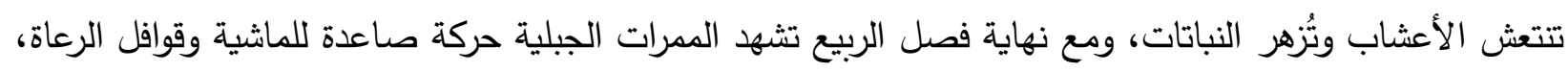

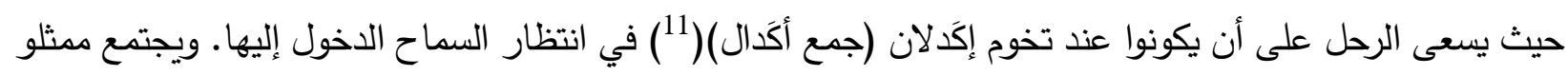

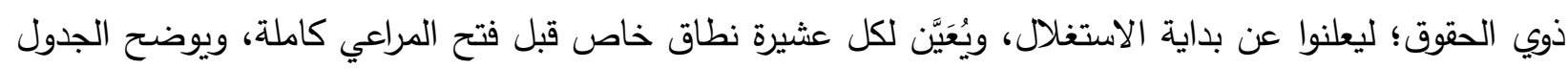
التالي ربط تسميات المراعي بذوي الحقوق:

جدول رقم2: بعض أسماء مراعي اتحادية آيت عطا وآيت سدرات الخاضعة لنظام أكدال

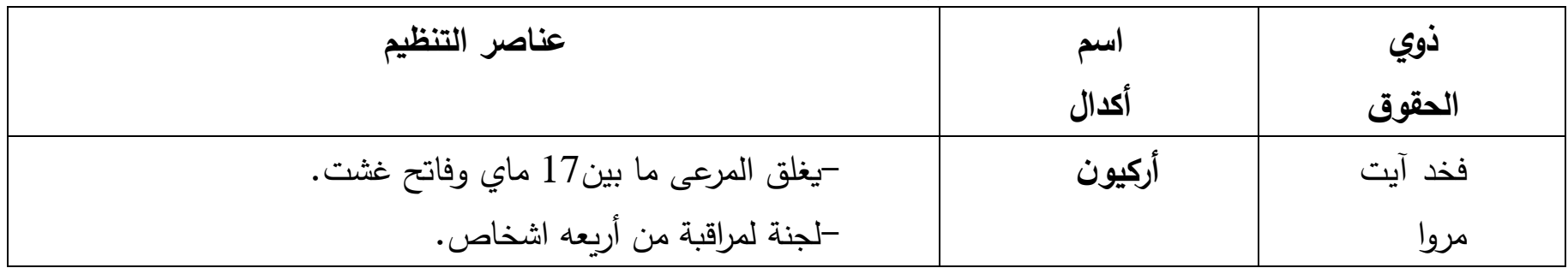




\begin{tabular}{|c|c|c|}
\hline - -حرية اختيار موضع الخيام. & & \\
\hline • . يغلق المرعى من ماي إلى يونيو. . تحديد الدعيرة في السوق. & أوجْكال & آيت \\
\hline - - يغلق المرعى ما بين 17 إبريل وفاتح غشت تحديد مواضع لجنة تنظيمية. & إديس & فخد آيت \\
\hline 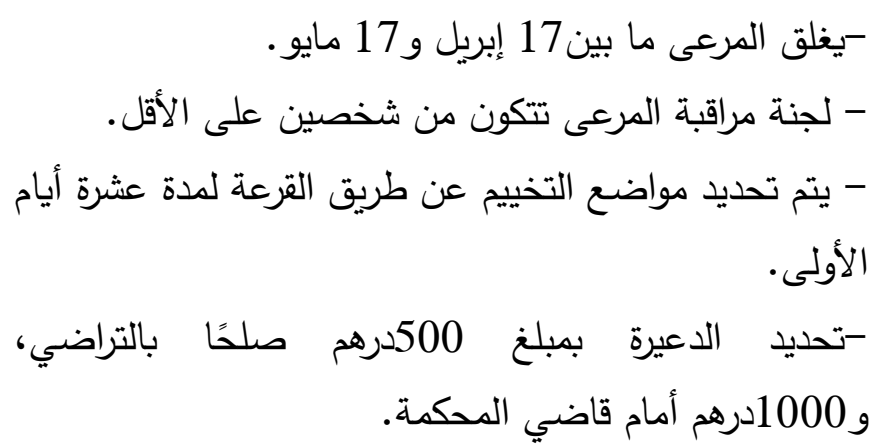 & أوزيغيمت & أفخاذ \\
\hline
\end{tabular}

$$
\text { المصدر: محمد آيت حمزة2012ص198 }
$$

فسكان آيت احمد يستغلون أكَال-ن - أُزيغدت بالمجال الترابي لأزيلال، وقد شيدوا فيها بُرجًا للمراقبة، ومخزنًا جماعيًا (تِغرمت-ن- آيت أحمد)، بينما تستغل أفخاد آيتا مُراوُ وآيت أوسكا أكَدال-أوجْكال-، ويُسمح لرعاة القبيلة جميعهم بتقديم حوالى 3000 رأس نحو أكَالنِ- إزْغار المشترك، وقد يحدث أن يتفق بعض الأشخاص، خاصة ذوي النفوذ، بصفة فردية، ممن يماثلهم عند قبائل أخرى على استغلال المسارح الجماعية في إطار المصالح المتبادلة.

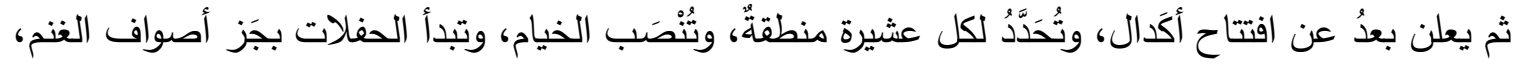
ويحضر الفقهاء والفقراء والمساكين؛ لينال كلٌّ نصيبه من الأفراح والزكوات، طيلة فصل الصيف، بخاصة إذا جادت المراعي بما لايها من أعثاب، حيث لا يغادرها الرعاة إلا بعد حلول الأعاصير الأولى واشتداد البرد (شتتبر / أكتوبر)،

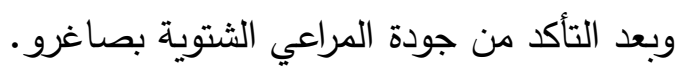

1-3-4 رحلة الثتاء نحو المراعي المنففضة بدير الأطلس الكبير الثرقي المركزي وجبال صاغرو

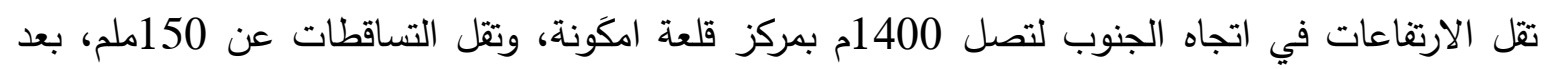
الخروج من الثنايا الأطلسية الكريطاسية والحادورات الرباعية المكوِنة لحوض دادس. وتصبح المسارح شبه عارية إلاه

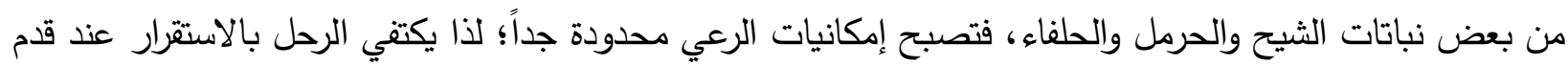

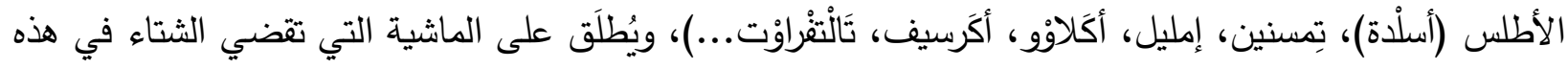
المناطق تِمَنْكَرسين، وقد يحدث في حالة جودة المراعي الصيفية أن يستغني الرعاة عن الصعود إلى القهم لقضاء الصيف على مقربة من الأدوية، مستغلين ما تزخر به الحقول من الخضر والفواكه، فيطلق عليها: (تِمصيفين) إذا تبين 
أن مراعي صاغرو أجود، ويتابع جزء من الماشية طريقه نحو الجنوب مخترقًا وادي دادس عند زاوية إماسين أو زاوية

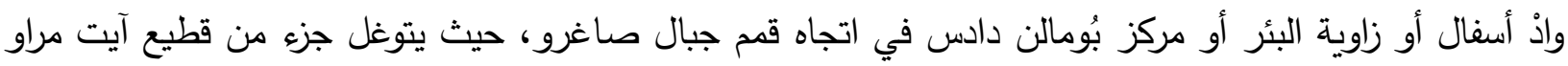

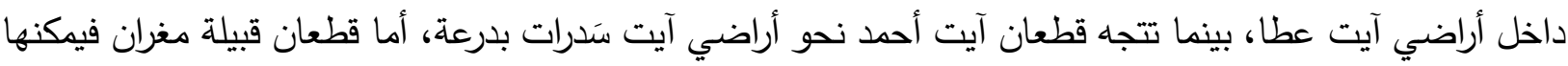
أن تصل حتى مسارح قبائل أهل ورزازات بمنطقة تازْناخت.

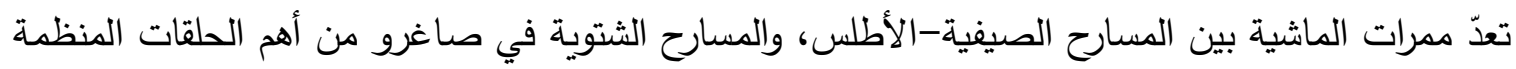

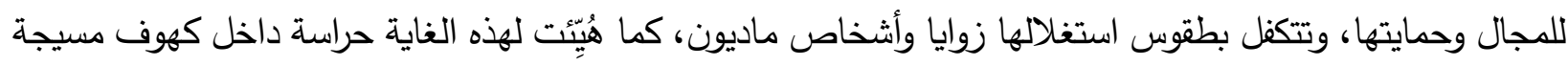

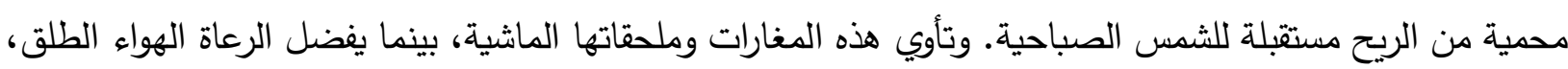

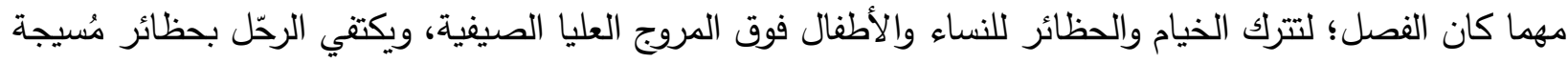

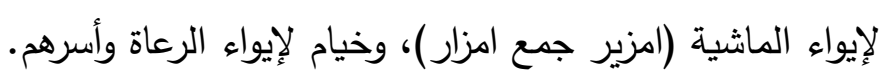

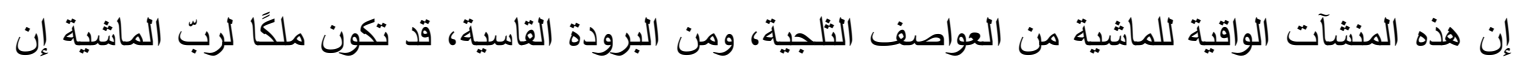

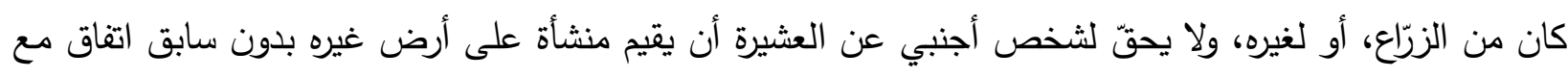
ذوي الحقوق.

هذا، ويسعى الفلاح إلى إقامة هذه المآوي عند أهم المراعي على طول الممرات الرئيسية للماشية؛ حتى يستفيد

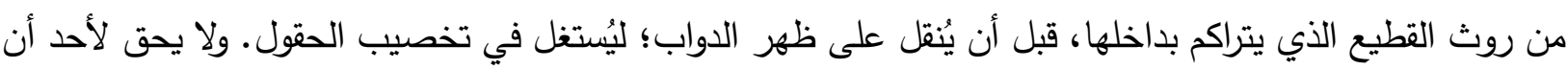

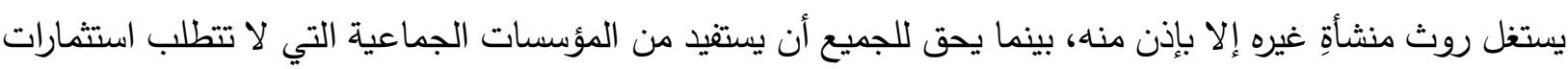

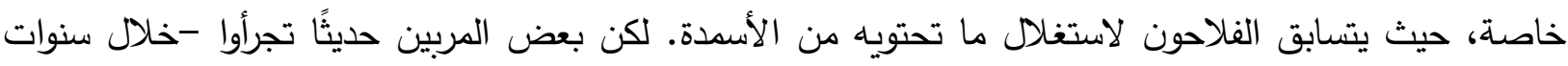

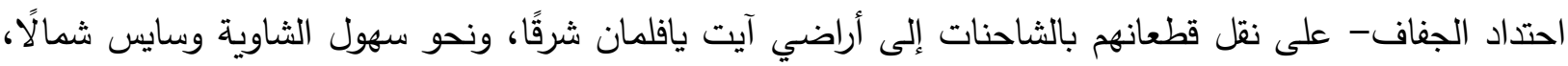

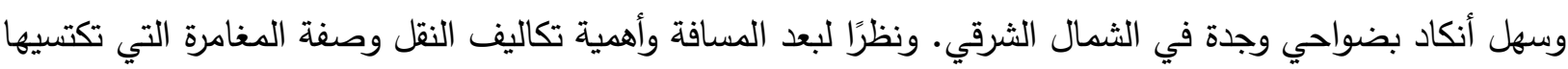

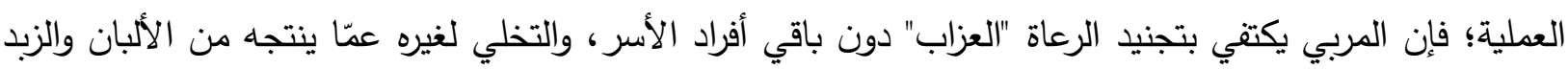

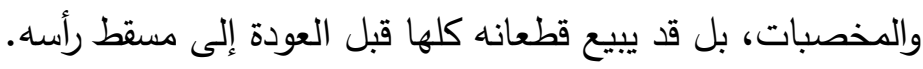

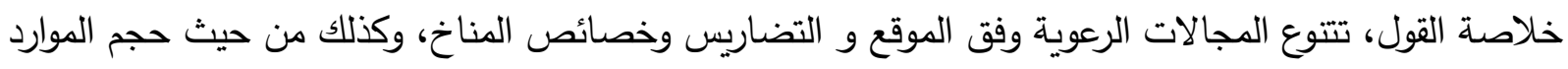

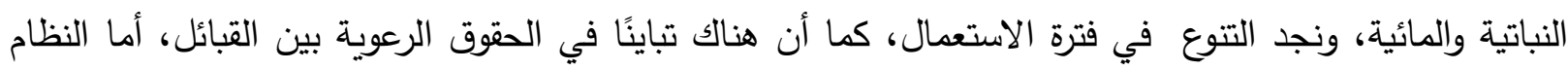

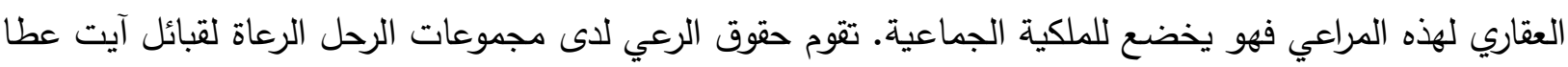

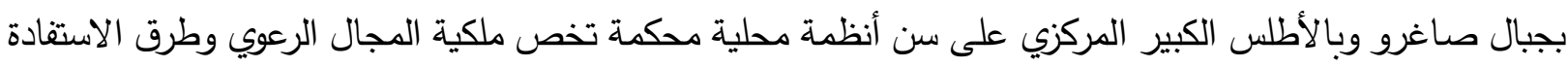

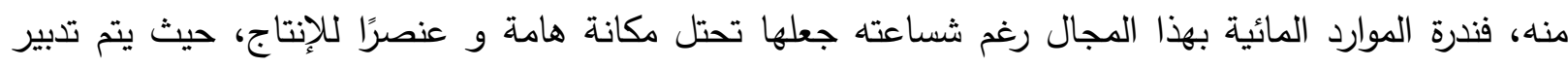

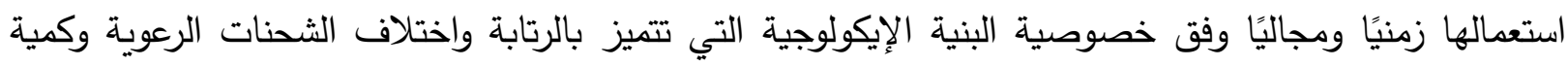

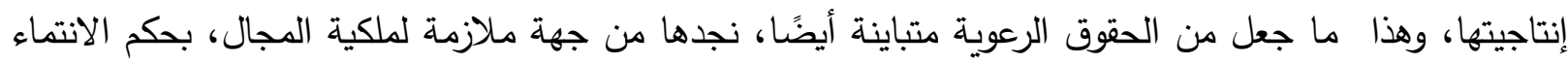

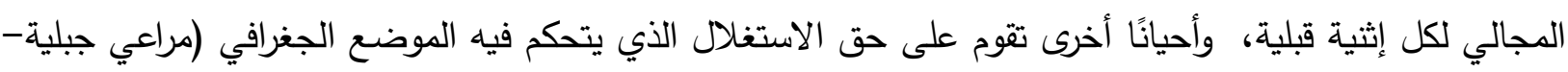
مراعي سهلية وهضبية) 


\section{2- مرحلة الاستقرار والتجديد في أشكال استغلال المجال الجبلي عند القبائل العطاوية بجبال صاغرو} والأطلس الكبير المركزي.

لقد انتقل نمط الحياة عند القبائل العطاوية بجبال صاغرو والأطلس الكبير المركزي من الانتجاع والترحال بحثًا

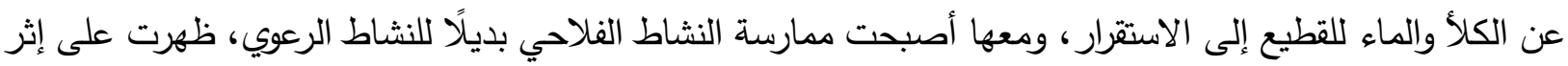

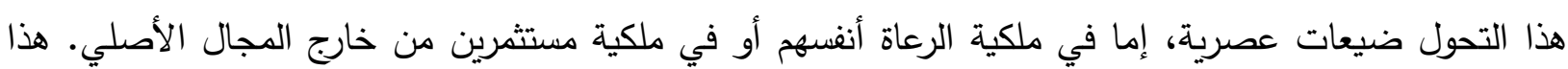
التحول تفسره عوامل، منها تعاقب سنوات الجفاف ومحدودية المراعي والتوسع العمراني، إضافة إلى تحكم الدولة ووصايتها الفعلية على المنطق الرعوية الجبلية.

1-2 طرق امتلاك العقار أساس للاستقرار عند القبائل العطاوية بجبال صاغرو.

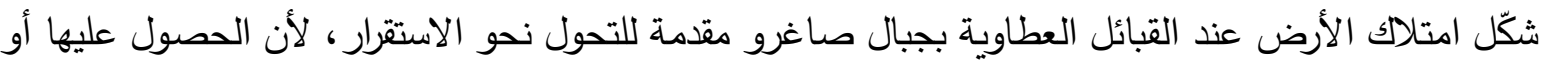

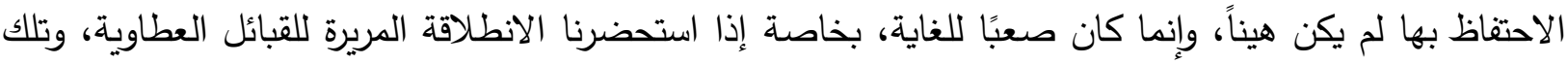

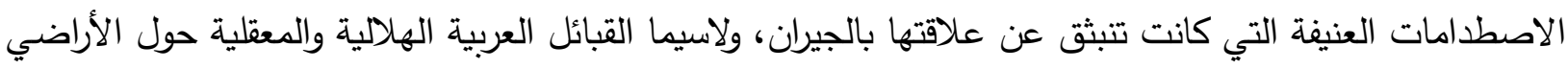

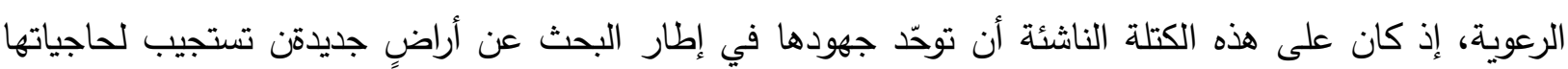
الايمغرافية المتزايدة، وتسمح لها بالخروج من صاغرو الذي لم يعد قادرًا على احتواء كل الفخدات والقبائل العطاوية.

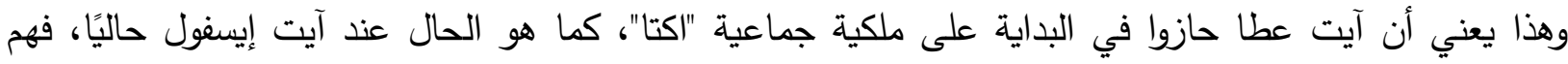

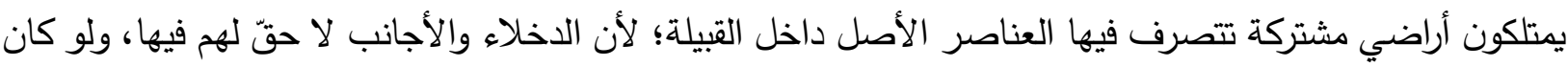

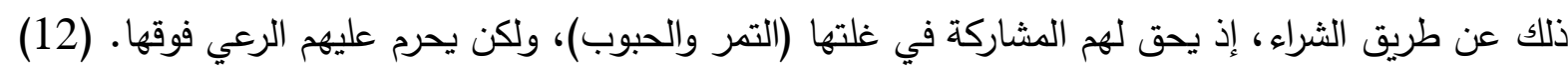

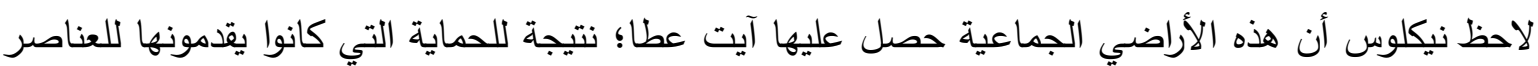

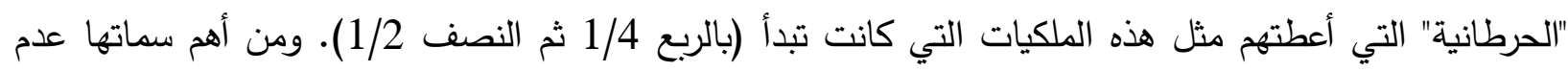

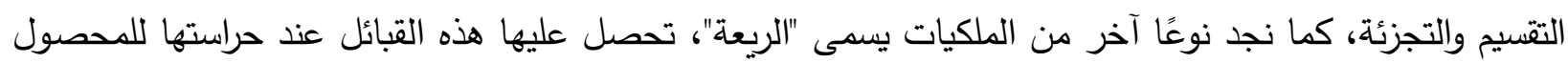

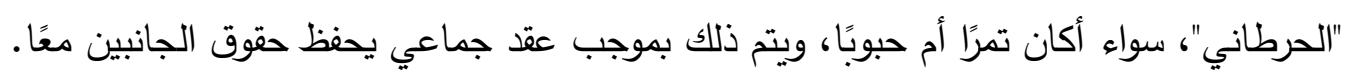

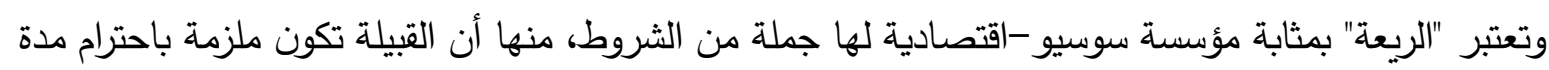

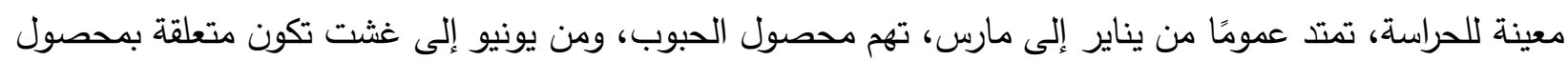

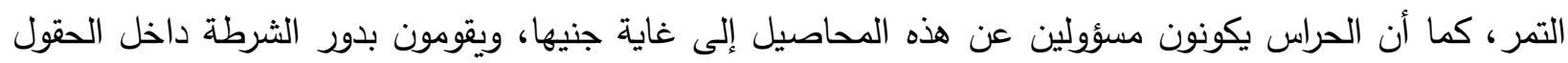

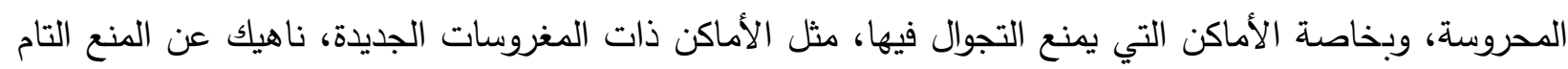

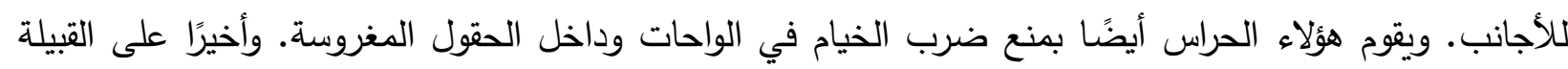

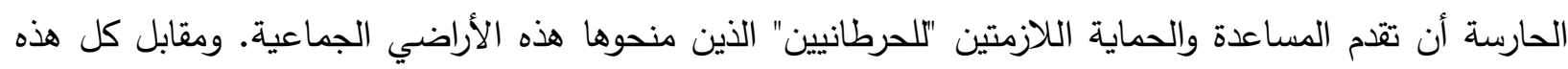

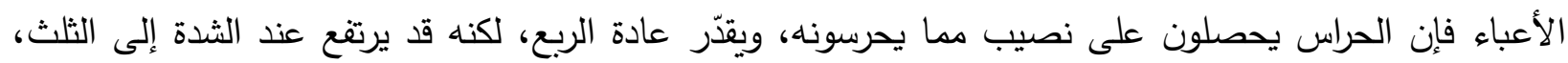

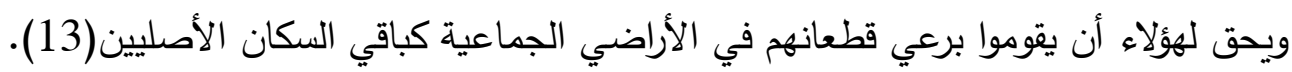

2-2 انتشار واسع للضيعات النموذجية للأشجار المثمرة مظهر من مظاهر الاستقرار بجبال صاغرو والأطلس الكبير المركزي

${ }^{(12)}$ Mezzine Larbi.Le Tafilalte.contribution à l'histoire du Maroc aux XVII et XVIII siècle. (Publications de la faculté des lettres et sciences Humaines, 1987, p.270

${ }^{(13)}$ Niclausse (C), les Ayt Atta du Sahara, centre des hautes études musulmanes, (C.H.E.M), N’2681,1956, p.2. 
يمكن الحديث عن الضيعات العصرية التي اجتاحت جل مناطق العالم، وبدأت بالتدريج في اكتساح المناطق الجافة والقاحلة، لما لها من فوائد اقتصادية، كالمساهمة في إنثاء فلاحة تسويقية تدر عائدات مالية مهمة للفلاح المرتبط بثكل مباشر وغير مباشر بالقطاع الفلاحي، إضافة إلى تدبير الموارد المائية عن طريق الاقتصاد في الاستهلاك، إلا أن لها انعكاسًا سلبيًا على المدى المتوسط والبعيد، ويتمثل أساسًا في استنزاف السديمة الباطنية.

وقد كانت المبادرة الأولى التي عرفتها المنطقة من طرف الخواص سنة2000، وهي محاولة لتعميم هذا النوع من الفلاحة التي انطلقت من سوس، والخريطة أسفله توضح هذا التوجه الجديد للضيعات الفلاحية.

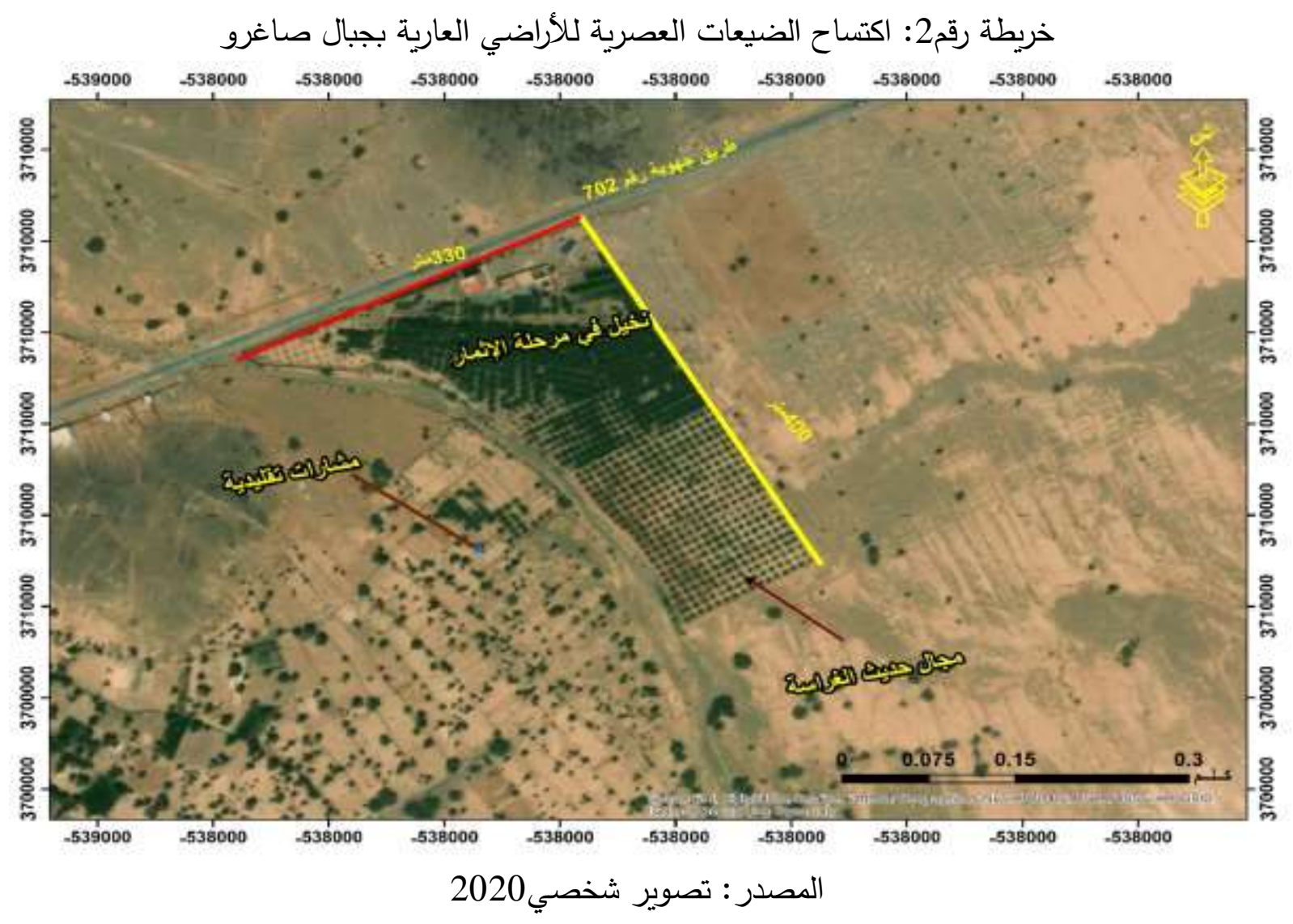

انطلاقًا من الخريطة أعلاه يتضح أن الضيعات العصرية بدأت تكتسح الأراضي العارية بجبال صاغرو، مستيدة من ظروف تضاريسية عند قدم الجبل، فالأرض تتسم بهامش كبير من الانبساط، ومن ظروف القرب من الموارد المائية التي يوفرها الوادي، سواء بشكل مباشر خلال الامتطاحات أو بشكل غير مباشر ارتباطًا باستغلال السديمة المائية. 
يتضح أن الأصل في الأنظمة الهيدروفلاحية المعتمدة في منطقة صاغرو هو انتشار محطات الضخ بالكازوال، لكن مع ارتفاع أسعار هذه المادة في الأسواق العالمية أرغم المستثرين في القطاع الفلاحي بالمنطقة على

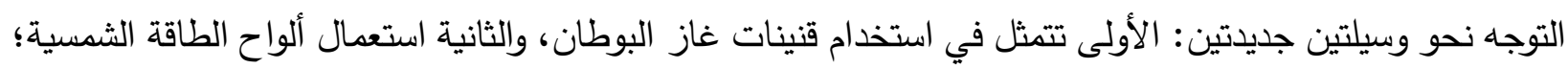
نظرًا لطول أيام التشميس ومستفيدين من الدعم الذي يوفره كل من مخطط المغرب الأخضر وصندوق المقاصة لقنينات الغاز ، كما يوضح الجدول التالي توزيع أنواع الطاقات المستعملة في ضخ المياه إلى حدود أبريل سنة 2019. إن قراءة المعطيات الإحصائية التي يوفرها الجدول توضح بشكل جلي اعتماد الطاقة الثمية وسيلة أساسية؛ لضخ المياه بنسبة62\%، بينما لا تتجاوز قنينات الغاز 36\% ، واستعمال طاقة الكازوال بنسبة 2\% بهـ جدول رقم2 يبين الطاقات المستعملة لضخ المياه بمنطقة صاغرو

\begin{tabular}{|c|c|c|c|}
\hline الثمسية & قنينات الغاز & الكازوال & وسيلة ضخ \\
\hline 62 & 36 & 02 & المئوية (النسبة \\
\hline
\end{tabular}

$$
\text { المكتب الجهوي للاستثمار الفلاحي تنغير } 2020
$$

نستتتج من هذا التوزيع أن الاعتماد على الطاقة البديلة والمتجددة بالجبال المغربية يرتبط بطول أيام التشميس، وبالتكلفة الاقتصادية المنخفضة، ونظافة هذه الطاقة، وعكس ذلك فإن ضعف الإقبال على الغاز والكازوال مرتبط بالتكلفة المرتفعة، على اعتبار استيرادهما من الخارج، ولا يعد الوطن بلدًا منتجًا لهما.

\section{2-2-2-الانعكاسات العامة للايناميات الفلاحية بجبال صاغرو}

لم تتشأ ظاهرة تدهور المجال الجبلي بخاصة في صاغرو دفعة واحدة، بل كان ظهورها بهذا الحجم نتيجة لتراكمات التعامل غير الرشيد مع الموارد الطبيعية، بسبب الضغط البشري والحيواني المفرط على هذا الوسط الهش، وبهذا أصبحت أغلب المناطق الجبلية بصاغرو الثاسعة غير صالحة لممارسة الزراعة، كما أن حفر آبار عديدة بدون مراقبة أدى إلى استنزاف مياه الفرشات الباطنية، وبالتالي جفاف معظم الآبار، وفي ظل سيادة الرعي الجائر وقطع النباتات تتعرض المراعي لتدهور خطير، أما الأراضي المرملة فتزداد مساحتها سنة بعد سنة على حساب الأراضي المستغلة، وتراجع أعداد النخيل والأشجار عامة بسبب الأمراض والتحطيب.

1-4-2 الانعكاسات الإيكولوجية.

. 1-4-2

يتميز مستوى الفرشة المائية بقربه من مستوى سطح الأرض، وهذا ما شجع على حفر آبار لا يتجاوز عمقها

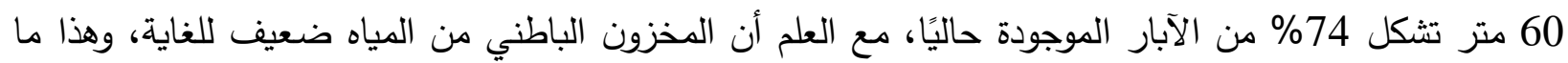
ينذر بازدياد عمق مستوى الآبار، بل إنه يهدد هذه الفرشة بالنضوب إذا استمرت وثيرة الضيعات العصرية النموذجية في التزايد.

$$
\text { مبيان رقم 2: مستوى عمق الآبار بجبال صاغرو }
$$




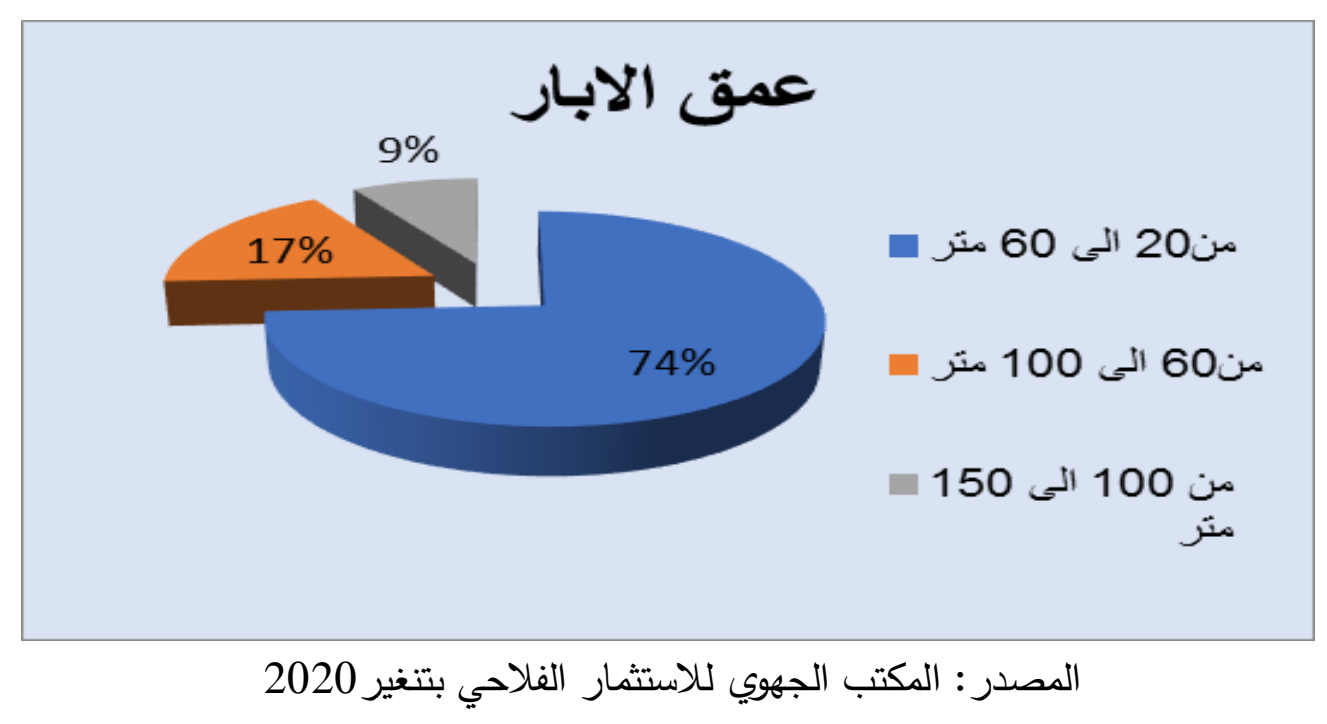

(ع-2-2-2 نقص خصوبة التربة واستفحال ظاهرة التصحر.

لعب استمرار عقود من الجفاف وتعاقب سنواته على المجال في تفاقم حدة التصحر وتراجع خصوبة التربة، فقد ساهدت الرياح مع عامل الاستغلال المكثف للتربة إلى تدهورها، وظهور الأخاديد والتشققات على الطبقة العليا نظرًا للسقي المفرط، إضافة إلى تملّحها، كما يعمل القطيع الرعوي على اندكاكها، ومن ثّّ فقدان قدرتها على دعم نمو النباتات والاحتفاظ بالرطوبة مما يؤدي إلى ازدياد التبخر وتسرب مياه السطح، وأخيرا إلى تعريتها.

3-1-4-2 البيوض: bayaude ويعد هذا المرض من أخطر الأمراض على الإطلاق، يصيب سعف النخيل المتوسط قبل

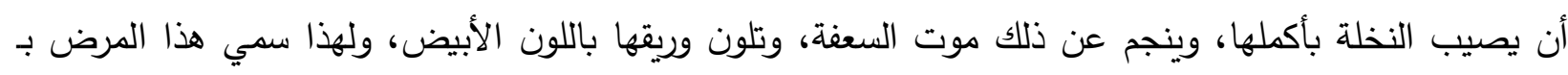
"البيوض" وينتقل عن طريق غرس الفسائل المصابة أو نقل أجزاء أخرى من النخلة المصابة أو عن طريق السقي وعمليات الحرث، إلى جانب أمراض السوسة والرتيلة...

2-2-2-الانعكاسات الاجتماعية والاقتصادية يمكن حصرها في العناصر الآتية: ظهور بورجوازية فلاحية مالكة للضيعات النموذجية، وتراكم رأسمال مهّ جراء تسويق أجود أصناف التمور، وحرمان الفلاحين الصغار من موارد دخل قارّ، وعدم قدرتهم على المنافسة، مما يجعلهم يعرضون خبرتهم وقدراتهم البدنية

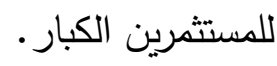

•استقحال ظاهرة الفقر والهجرة القروية، نحو المركز الحضري؛ لتنغير وتتجداد أو خارجهما. ظهور أمراض تصيب الجسد البشري كالليشمانية والرماد الحبيبي. •ارتفاع أثمنة أسعار الخضر والفواكه وسومة العقار • 
تقنين حفر الآبار، والدعوة إلى تحمّل وكالة الحوض المائي لزيز كير غريس مسؤوليتها القانونية باعتبارها السلطة المانحة لرخص حفر الآبار .

مخاطبة المستثرين في الميدان بخصوص الصهاريج المائية المقامة هناك، وتحسيسهم بأن الثكل الذي يتبعونه

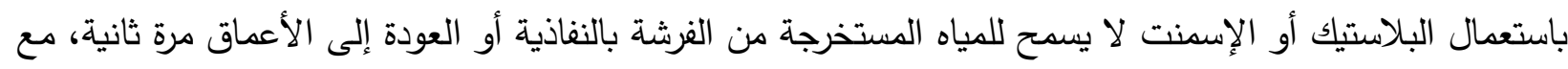

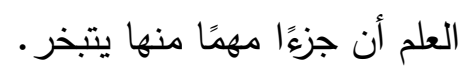
الدعوة إلى استعمال قتينات الفخار في ري أثجار النخيل باعتبارها طريقة بيولوجية تساهم في اقتصاد استهلاك الماء بحيث لا تأخذ النخلة إلا ما هي بحاجة ماسة من الماء.

الخاتمة

يتضح مما سبق أن الظروف الطبيعية في المجال الجبلي بصاغرو حاضرة بقوة من خلال شح التساقطات وعدم انتظامها السنوي وارتفاع درجات الحرارة، إضافة إلى الضغط الديموغرافي المتزايد، وتغيّر في طبيعة الوظائف الأصيلة للمجالات الجبلية وانفتاحها على وظائف جديدة، وتدخّل الدولة والقطاع الخاص والمنظمات الحكومية وغير الحكومية بمشاريع مندمجة، تؤثر كلّها على تغيّر المنظومة المشهدية للبيئة الجبلية بالجنوب الشرقي المغربي.

المصادر والمراجع

• آيت حمزة محمد، 1993. التوازن الإيكولوجي الواحي بين التتافس والتكامل، المجال والمجتمع بالواحات المغربية، منشورات كلية الآداب والعلوم الإنسانية مكناس، سلسلة الندوات رقمبك. • استيتيتو عبد الله، 2011 التاريخ الاجتماعي والسياسي لقبائل آيت عطا الصحراء إلى نهاية القرن التاسع عشر ، منشورات المعهد الملكي للثقافة الأمازيغية، مطبعة المعارف الجديدة-الرباط.

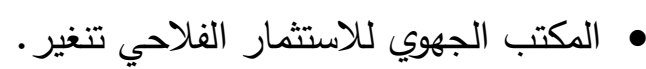

• الناصري محمد.2003، الجبال المغربية. مركزيتها -هامشيتها - تتميتها منشورات وزارة الثقافة، مطبعة دار المناهل

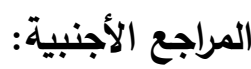

- $\quad$ AIT HAMZA.M, 2002 : Mobilité socio spatiale et développement local au sud de l'Atlas marocain (Dades-Todgha), Thèse Publiées à Passau en Allemagne, in Maghreb Studien,N 13.

- C, Niclausse, les Ayt Atta du Sahara, centre des hautes études musulmanes, (C.H.E.M), $\mathrm{N}^{\circ} 2681,1956$

- Laurent Auclair et Mohamed Alifriqui, 2012, Agdal patrimoine socio-écologique de l'atlas Marocain, RD.

- Mezzine Larbi, Le Tafilalte.contribution à l'histoire du Maroc aux XVII et XVIII siècle, publications de la faculté des lettres et sciences humaines, 1987, p.270

- Pascon Paul, le Haouz de Marrakech, vol2, Tanger, Edition marocaine et internationales1983. 